\title{
RECOVERY OF THE BIRD POPULATION WITHIN PINE FORESTS AFTER THE CATASTROPHIC FIRES IN 2010
}

(C) 2017

Sorokina Julia Alexandrovna, postgraduate student of Botany and Zoology Department

Boryakova Elena Evgenievna, candidate of biological sciences, associate professor of Botany and Zoology Department

National Research Lobachevsky State University of Nizhny Novgorod (Nizhny Novgorod, Russian Federation)

Abstract. Process of bird population restoration after fires was investigated in two protected areas in the Volga river basin in central Russia. Anthropogenic pressure in Kerzhensky and Mordovsky nature reserves is very low, it made possible to discover some characteristics of the process of bird population restoration in reference environment. The counts were carried out both in the affected areas of the reserves, and in unaffected parts. The studied area was in its five year after the fire. Dynamics of post fire bird population restoration and its dependence on both the age and history of the original ecosystems were investigated. The authors present the results of dominant species analysis and information about their distribution in the investigated natural reserves. The authors show peculiarities and proportions of ecological groups of birds in the studied territories as well as their proportion. The influence of hydrological parameters on bird communities composition was investigated, it turned out that post fire partial inundation leads to increase of waders of Gallinago and Tringa genera. Species diversity of bird communities in affected areas was considered. Using Pielou's index it was found that species evenness remained relatively high, i.e. no significant increase of dominance was observed after the fires. The authors analyzed the composition of ornitocomplexes in terms of different faunistic groups.

Keywords: bird population; pyrogenic succession; pyrogene-dependent communities; Kerzhensky reserve; fires; ornitofauna; Mordovsky Reserve; species of forest margins; forest birds; species richness; pine birch wood; high bogs; breeding period; postbreeding period; biodiversity; uniformity; lack of uniformity.

УДК $575.2+582.29$

Статья поступила в редакцию 20.10.2017

\section{ОНТОГЕНЕТИЧЕСКАЯ ИЗМЕНЧИВОСТЬ МОРФОЛОГИЧЕСКИХ ПРИЗНАКОВ ЭВЕРНИИ СЛИВОВОЙ (EVERNIA PRUNASTRI (L.) ACH.) НА РАЗНЫХ ВИДАХ ДЕРЕВЬЕВ В РАЗЛИЧНЫХ ЭКОЛОГИЧЕСКИХ УСЛОВИЯХ}

(C) 2017

Суетина Юлия Геннадьевна, кандидат биологических наук, доцент кафедры биологии Марийский государственный университет (г. Йошкар-Ола, Российская Федерация)

Аннотащия. В статье рассматривается изменчивость количественных морфологических признаков эпифитного лишайника E. prunastri. Исследования проведены на территории Республики Марий Эл в липняках в пойме реки Большая Кокшага. Слоевища E. prunastri разных онтогенетических состояний $\left(\mathrm{v}_{1}, \mathrm{v}_{2}, \mathrm{~g}_{1} \mathrm{v}, \mathrm{g}_{2} \mathrm{~V}, \mathrm{~g}_{3} \mathrm{v}\right.$, ss) были собраны на Tilia cordata, Padus avium, Quercus robur на высоте ствола от 0,5 до 2 м и на ветвях Abies sibirica на высотах 3-4 м, 5-6 м, 7-8 м. По большинству признаков Tilia cordata является наиболее благоприятным субстратом для развития слоевищ E. prunastri. Признак, характеризующий развитие слоевища (длина слоевища), имеет минимальные размеры на Padus avium. Признаки отмирания (число отмерших веточек, длина почернения корового слоя) максимальны на Padus avium, что свидетельствует о более ускоренных процессах старения слоевища на данном форофите. Слоевища E. prunastri, произрастающей на ветвях Abies sibirica, имеют наибольшие размеры на высотах 3-4 и 5-6 м по сравнению с высотой 7-8 м. На бо́льших высотах формируются более длинные сорали, следовательно, образуется больше соредий. Значения большинства признаков E. prunastri, произрастающей в правобережье реки Большая Кокшага, больше, чем в левобережье, что связано с различиями в освещённости местообитаний. Длина соралей в правобережье (лучшая освещённость) больше на Quercus robur по сравнению с Tilia cordata. Изменчивость морфологических признаков по-разному проявляется в разных онтогенетических состояниях.

Ключевые слова: эпифитный лишайник; кустистый лишайник; Evernia prunastri; субстрат; форофит; ствол дерева; ветви дерева; Abies sibirica; Quercus robur; Tilia cordata; Padus avium; онтогенез; онтогенетические состояния; морфологические признаки; изменчивость; приспособленность; экологические условия; пойменные липняки; река Большая Кокшага; Республика Марий Эл.

\section{Введение}

Лишайники, как высокоспециализированные симбиотические организмы, колонизируют экстремальные местообитания, где они часто являются более успешными по сравнению с сосудистыми растениями и мхами как по биоразнообразию, так и по биомассе [1]. Многочисленные исследования показали, что такие черты, как морфология, анатомия, физиология и размножение, являются пластичными в ли- шайниках [2-9]. Изучение изменчивости количественных морфологических вегетативных и репродуктивных признаков лишайников на разных этапах индивидуального развития представляет интерес с позиции оценки приспособленности популяций к меняющимся условиям среды. Внутрипопуляционная адаптивная морфологическая изменчивость выявлена, например, в условиях влажных морских побережий у Ramalina menziesii Tayl. [10; 11], в тунд- 
ровых условиях - у Stereocaulon alpinum Laur. [12] Показано, что высокая морфологическая и генетическая изменчивость Cladonia rei Schaer. обусловливает колонизацию антропогенных субстратов [13]. Изменчивость морфологических и анатомических признаков, определенная условиями обитания, исследована у листоватых и кустистых лишайников [14; 15]. Изменчивость морфологических признаков в разных онтогенетических состояниях лишайников, вызванная адаптациями к условиям городской среды, показана на примере листоватых лишайников Xanthoria parietina (L.) Th. Fr. [16], Physcia stellaris (L.) Nyl. [17]; в природных местообитаниях - на примере $U s$ nea florida (L.) Weber ex F.H. Wigg. [18], Hypogymnia physodes (L.) Nyl. [19]. Вегетативно размножающиеся лишайники представляют значительный интерес для популяционных исследований в связи с высокой морфологической пластичностью. Целью работы является изучение изменчивости морфометрических признаков в онтогенезе Evernia prunastri (L.) Ach., произрастающей на разных форофитах в разных экологических условиях. Эти исследования дополняют накопленные к настоящему времени материалы по структуре популяций этого вида [20; 21].

\section{материал и методы исследований}

Исследования проводили в Республике Марий Эл в пойме реки Большая Кокшага. Основываясь на принципах дискретного выделения онтогенетических состояний в онтогенезе растений [22; 23], ранее был изучен и описан онтогенез E. prunastri - соралиеобразующего эпифитного лишайника уплощенокустистой биоморфы [21]. Слоевища разных онтогенетических состояний были собраны на высоте ствола от 0,5 до 2 м на разных видах деревьев в разных местообитаниях (м/о) в июле 2009-2010 гг.: на дубе черешчатом (Quercus robur L.) - в дубо-липняке ландышевом (м/о 1); на черемухе обыкновенной (Padus avium Mill.) и на липе сердцелистной (Tilia cordata Mill.) - в липняке черемухово-страусниковом (м/о 2); на липе - в липняке страусниково-ландышевом (м/о 3); на ветвях модельного дерева пихты сибирской (Abies sibirica Ledeb.) на высотах 3-4 м, 5-6 м, 7-8 м - в елово-пихтовом дубо-липняке страусниковом. Для оценки влияния экологических условий местообитаний (разной освещенности) на изменчивость признаков E. prunastri слоевища собирали в сентябре 2013 г. на липе и дубе в елово-пихтовом дубо-липняке страусниковом (правобережье) и дубо-липняке ландышевом (левобережье). Оценку освещённости в этих двух местообитаниях проводили в 2009 г. с использованием прибора ТКА-ПКМ. Показано, что наименее освещённым местообитанием является дубо-липняк ландышевый (левобережье) по сравнению с елово-пихтовым дубо-липняком страусниковым (правобережье) [24]. Для исследования изменчивости признаков в онтогенезе были выбраны по 15 слоевищ $\mathrm{V}_{1}$-SS онтогенетических состояний. Изучение морфометрических признаков (число отмерших веточек, число дихотомических ветвлений, длина почернения корового слоя, число соралей и длина соралей на одной основной веточке) проводили с помощью бинокулярного микроскопа - МБС 10; длину слоевища измеряли с помощью линейки. В v2 состоянии было исследовано от 2 до 10 соралей, у потенциально генеративных особей $\left(\mathrm{g}_{1} \mathrm{v}, \mathrm{g}_{2} \mathrm{v}, \mathrm{g}_{3} \mathrm{v}\right)$ - по 10 соралей. В работе применяли двухфакторный и трехфакторный дисперсионный анализ, при множественных сравнениях - Шеффе-тест. Использовали программу «Statistica 6.0».

\section{Результаты и их обсуждение}

Изменчивость морфометрических признаков в онтогенезе E. prunastri, произрастающей на стволе разных форофитов в разных экологических условияx. Двухфакторный дисперсионный анализ показал, что для всех признаков статистически значимо влияние фактора онтогенетическое состояние $(\mathrm{P}<0,001)$, фактора субстрат $(\mathrm{P}<0,001)$. Взаимодействие факторов онтогенетическое состояние-субстрат выявляется на 5\% уровне для признака длина соралей, для остальных признаков - $\mathrm{P}<0,01-0,001$.

На дубе, липе и черемухе прослеживается одинаковая тенденция - возрастание значений длины слоевища до максимума в $\mathrm{g}_{3} \mathrm{~V}$ состоянии с последующим уменьшением в ss онтогенетическом состоянии (рис. 1). Аналогичные результаты изменения размеров слоевища в онтогенезе характерны, например, для листоватого лишайника Xanthoria parietina [16] и для кустистого лишайника Usnea florida [18]. Минимальная длина слоевища отмечена на черемухе. Поскольку липа и черемуха произрастают в одном местообитании, то различия по длине слоевища связаны не с экологическими условиями местообитания, а с особенностями субстрата. При этом на черемухе слоевища имеют меньшие значения длины слоевища в $\mathrm{g}_{1} \mathrm{~V}$ и $\mathrm{g}_{2} \mathrm{~V}$ состояниях. Большие значения длины слоевища характерны для $\mathrm{g}_{3} \mathrm{~V}$ особей на липе в м/o 2 .

Число дихотомических ветвлений увеличивается от $\mathrm{v}_{1}$ до $\mathrm{g}_{1} \mathrm{v}$ состояния, потенциально генеративные особи не различаются между собой, в ss состоянии происходит уменьшение их числа (рис. 2). Минимальное значение числа дихотомических ветвлений характерно для слоевищ, растущих на липе в м/о 3 . Слоевища, растущие на дубе, черемухе и липе в м/о 2 , по числу дихотомических ветвлений не различаются. Следует отметить, что изменение этого признака происходит по-разному на разных субстратах в разных онтогенетических состояниях: на дубе возрастание числа дихотомических ветвлений происходит от $\mathrm{v}_{1}$ до $\mathrm{g}_{2} \mathrm{~V}$ состояния, на черемухе и на липе в м/o 2 - до $\mathrm{g}_{3} \mathrm{~V}$ состояния, на липе в м/о 3 особи потенциально генеративного периода не различаются между собой.

Изменение длины почернения корового слоя, свидетельствующее об интенсивности его отмирания, начинается в $\mathrm{v}_{2}$ онтогенетическом состоянии. Максимальные значения характерны для ss особей, резко отличающиеся от потенциально генеративных особей. На черемухе в $\mathrm{g}_{3} \mathrm{~V}$ и ss состояниях отмечена максимальная длина почернения корового слоя. Особи $\mathrm{g}_{2} \mathrm{~V}$ состояния на липе в м/о 3 резко отличаются большими значениями признака от $\mathrm{g}_{2} \mathrm{~V}$ особей, растущих на других субстратах.

Отмершие веточки появляются в $\mathrm{v}_{2}$ онтогенетическом состоянии. Особи $\mathrm{v}_{2}, \mathrm{~g}_{1} \mathrm{v}$ и $\mathrm{g}_{2} \mathrm{v}$ онтогенетических состояний не различаются между собой, их число резко возрастает в $\mathrm{g}_{3} \mathrm{~V}$ и ss состояниях (рис. 3). На черемухе отмечено максимальное число отмерших веточек, что свидетельствует о более ускоренных процессах старения слоевища на данном субстрате. Взаимодействие факторов онтогенетическое 
состояние-субстрат высоко значимо, максимальное значение числа отмерших веточек в $\mathrm{g}_{3} \mathrm{~V}$ и ss состояниях отмечено на черемухе, на других субстратах онтогенетические состояния не различаются по этому признаку. Начиная с $\mathrm{v}_{2}$ состояния отмечено отмирание корового слоя и появление остатков отмерших веточек и у кустистого лишайника Usnea florida [18].

Сорали появляются у $\mathrm{v}_{2}$ особей, их количество увеличивается до $\mathrm{g}_{3} \mathrm{~V}$ состояния, у ss особей происходит уменьшение их числа (рис. 4), что связано с тем, что сорали сливаются между собой и увеличивается их размер. Липа в м/о 3 отличается от остальных субстратов меньшим числом соралей. Максимальные значения числа соралей - на дубе, черемухе и липе в м/о 2 в $\mathrm{g}_{2} \mathrm{~V}$ и $\mathrm{g}_{3} \mathrm{~V}$ состояния, а на липе в м/о 3 максимум приходится на $\mathrm{g}_{3} \mathrm{v}$ состояние. Длина со-

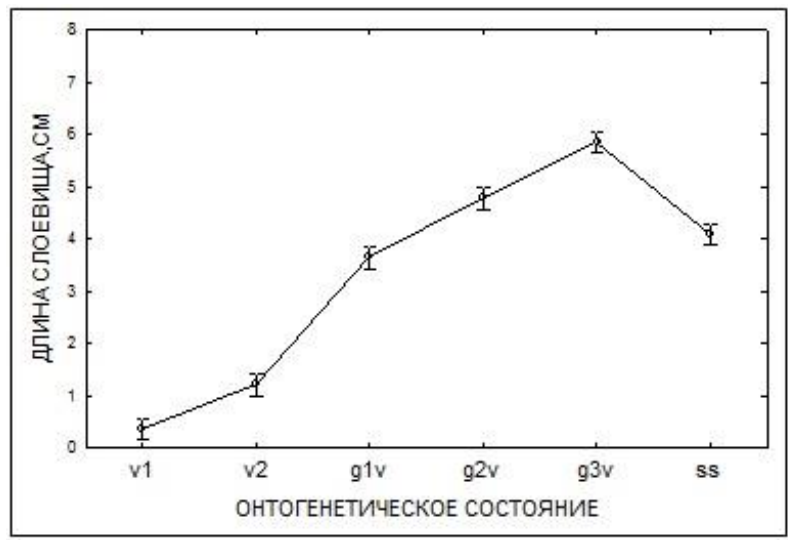

a) в онтогенезе ралей увеличивается от $\mathrm{v}_{2}$ до $\mathrm{g}_{3} \mathrm{~V}$ онтогенетического состояния, y $\mathrm{g}_{3} \mathrm{~V}$ и ss особей их длина не различается. В м/о 2 длина соралей больше на липе, чем на черемухе. Максимальная длина соралей отмечена у слоевищ, растущих на черемухе в ss состоянии, на липе в $\mathrm{g}_{3} \mathrm{~V}$ и $\mathrm{ss}$ состояниях.

Изучение изменчивости морфометрических признаков проводили в онтогенезе E. prunastri, произрастающей в разных условиях освещенности, поскольку известно, что E. prunastri является видом, требовательным к свету [25]. Здесь приводятся результаты трехфакторного (факторы местообитание, онтогенетическое состояние, субстрат) дисперсионного анализа. Поскольку изменения признаков в онтогенезе аналогичны выше рассмотренным, они не обсуждаются.

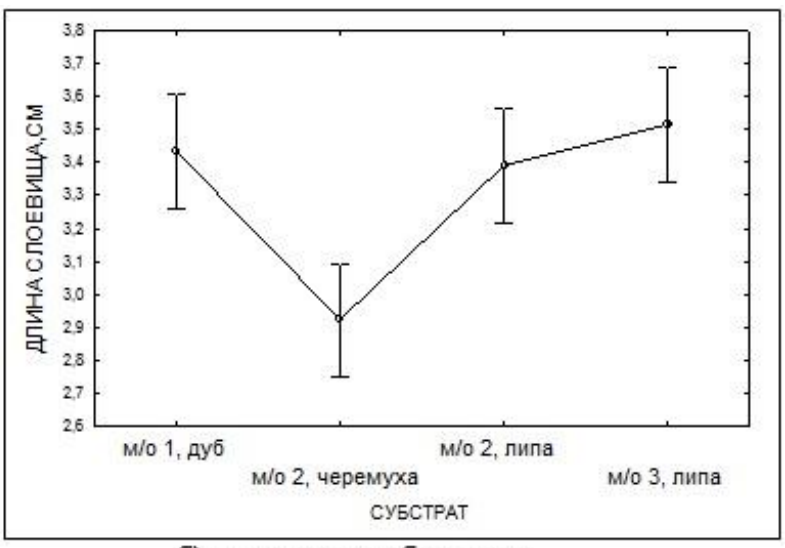

б) на разных субстратах

Рисунок 1 - Изменение длины слоевища E. prunastri, произрастающей на стволе дерева

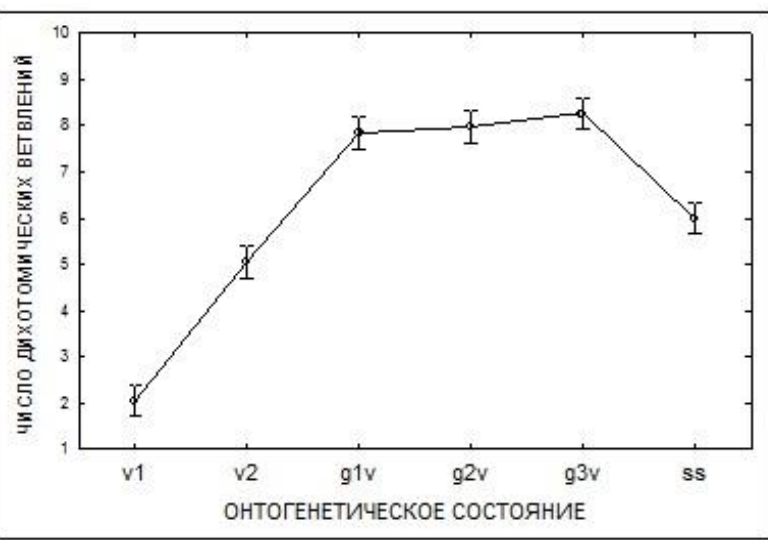

a) в онтогенезе

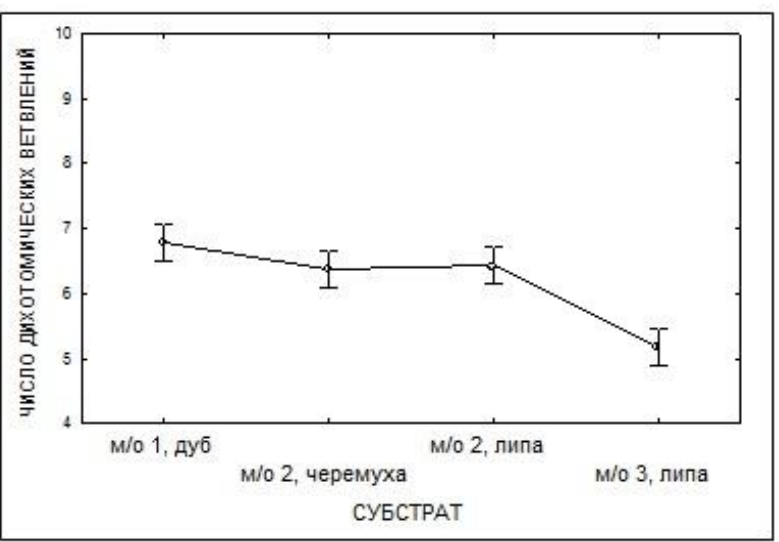

б) на разных субстратах

Рисунок 2 - Изменение числа дихотомических ветвлений E. prunastri, произрастающей на стволе дерева

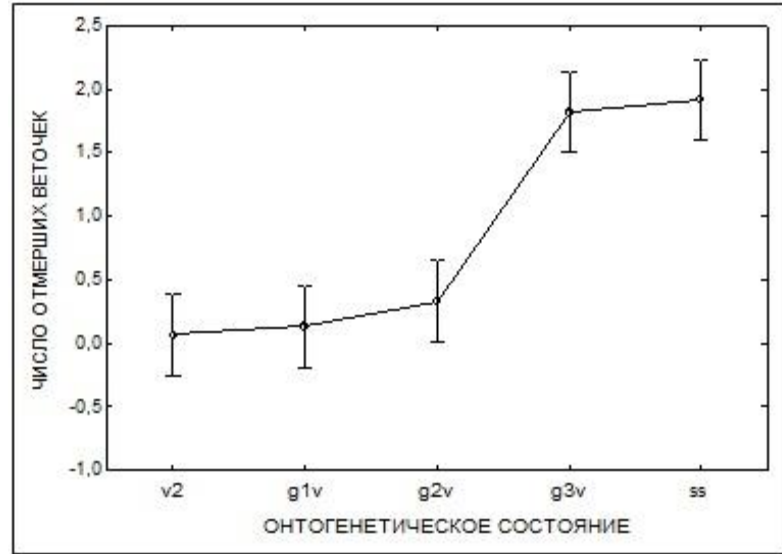

a) в онтогенезе

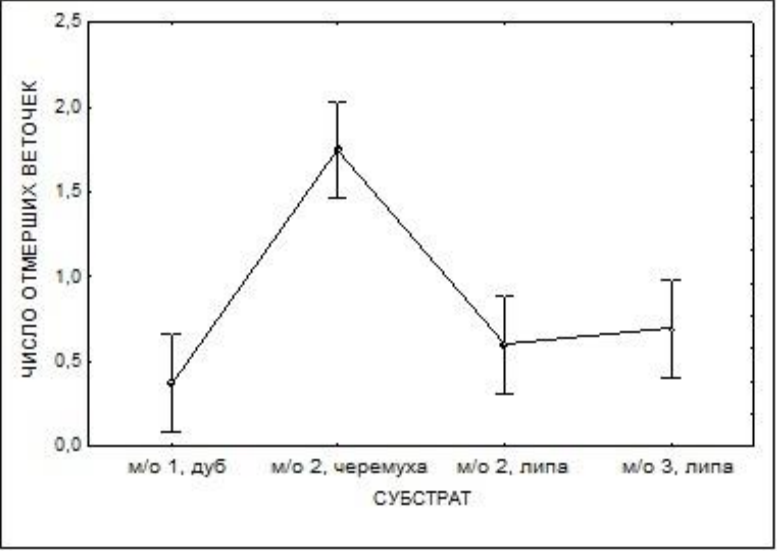

б) на разных субстратах

Рисунок 3 - Изменение числа отмерших веточек E. prunastri, произрастающей на стволе дерева 


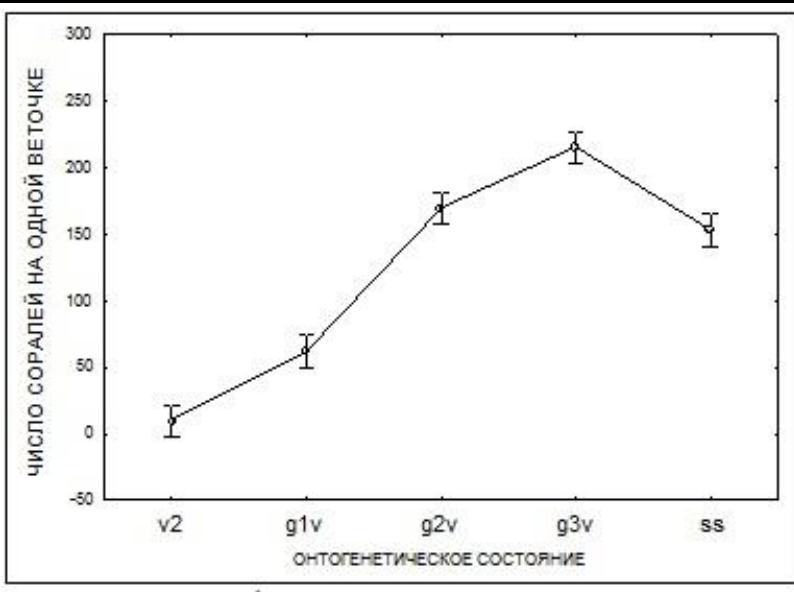

a) в онтогенезе

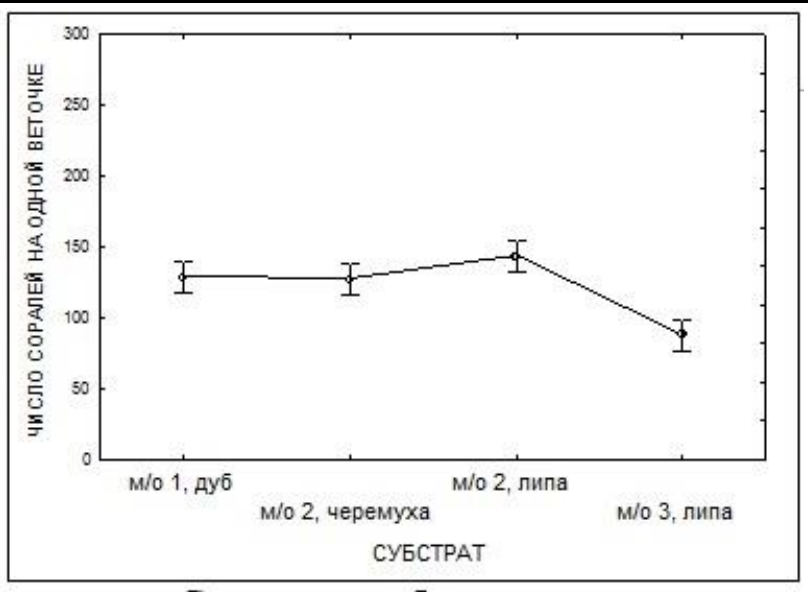

б) на разных субстратах

Рисунок 4 - Изменение числа соралей E. prunastri, произрастающей на стволе дерева

Для длины слоевища на 5\% уровне значим фактор местообитания $(\mathrm{P}=0,047)$. На изменчивость данного признака высоко значимое влияние оказывает фактор онтогенетическое состояние $\left(\mathrm{P}<10^{-6}\right)$. Длина слоевища E. prunastri имеет тенденцию увеличения в правобережье, которое находится в условиях лучшей освещённости.

Статистически значимыми в изменении числа дихотомических ветвлений являются факторы - местообитание $(\mathrm{P}=0,041)$ и онтогенетическое состояние $\left(\mathrm{P}<10^{-6}\right)$, а также взаимодействия факторов: местообитание-онтогенетическое состояние $(\mathrm{P}=0,042)$, субстрат-онтогенетическое состояние $(\mathrm{P}=0,002)$, местообитание-субстрат-онтогенетическое состояние $(\mathrm{P}=0,042)$. Данный признак различается у слоевищ в $\mathrm{V}_{1}$ состоянии; число дихотомических ветвлений на липе является бо́льшим по сравнению с дубом, различия выявлены в правобережье.

Длина почернения корового слоя E. prunastri зависит от факторов местообитание $(\mathrm{P}=0,01)$ и онтогенетическое состояние $\left(\mathrm{P}<10^{-6}\right)$, на $5 \%$ уровне значимо взаимодействие местообитание-субстрат. Длина почернения корового слоя E. prunastri на дубе в правобережье превышает соответствующие значения на дубе в левобережье, в то же время на липе различий в право- и левобережье не выявлено. По числу отмерших веточек в пределах каждого онтогенетического состояния распределения слоевищ в разных местообитаниях и на разных субстратах статистически значимо не различаются (точный критерий Фишера, $\mathrm{P}=0,37)$.

На изменчивость числа соралей E. prunastri оказывают влияние факторы субстрат $(\mathrm{P}=0,04)$ и онтогенетическое состояние $\left(\mathrm{P}<10^{-6}\right)$. Число соралей на дубе черешчатом превышает значения на липе на $5 \%$ уровне значимости. На изменчивость длины соралей E. prunastri влияют все три фактора $\left(\mathrm{P}<10^{-6}\right)$, а также все взаимодействия факторов $\left(\mathrm{P}<0,01-10^{-6}\right)$. Длина соралей в правобережье больше на дубе черешчатом по сравнению с липой сердцелистной, различия наблюдаются в $\mathrm{g}_{2} \mathrm{~V}$ и $\mathrm{g}_{3} \mathrm{~V}$ онтогенетических состояниях. Значения признака не различаются на липе сердцелистной в право- и левобережье.

Изменчивость морфометрических признаков E. prunastri, произрастающей на ветвях Abies sibirica. Двухфакторный дисперсионный анализ показал, что для всех признаков статистически значимо влияние фактора онтогенетическое состояние $(\mathrm{P}<0,001)$. Фак- тор высота высоко значим для числа отмерших веточек, и длины соралей $(\mathrm{P}<0,01-0,001)$, не значим для признака число соралей (Р>0,05), для остальных признаков значимость выявляется на 5\% уровне. Взаимодействие факторов онтогенетическое состояниевысота высоко значимо для числа дихотомических ветвлений, числа отмерших веточек, числа соралей, длины соралей $(\mathrm{P}<0,01-0,001)$.

Изменение длины слоевища, числа отмерших веточек, длины почернения корового слоя, числа и длины соралей в онтогенезе происходит так же, как и на стволе дерева. Наибольшие по длине слоевища

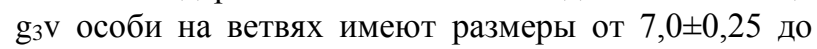
$7,8 \pm 0,39$ см, в то время как на стволе дерева длина слоевища варьирует от $5,3 \pm 0,38$ до $6,7 \pm 0,46 \mathrm{~cm}$. Больший размер слоевища имеют на высотах 3-4 м и 5-6 м, минимальная длина слоевища зафиксирована на высоте 7-8 м.

Число дихотомических ветвлений увеличивается от $\mathrm{v}_{1}$ до $\mathrm{g}_{3} \mathrm{~V}$ состояния с последующим уменьшением в ss состоянии. На разных высотах число дихотомических ветвлений не различается. Взаимодействие факторов онтогенетическое состояние-высота: на высоте 3-4 м по сравнению с другими высотами бо́льшие значения имеют $\mathrm{g}_{1} \mathrm{~V}$ особи, на высотах 56 м и 7-8 м бо́льшие значения характерны для $\mathrm{g}_{3} \mathrm{~V}$ особей.

С увеличением высоты происходит уменьшение числа отмерших веточек. Взаимодействие факторов онтогенетическое состояние-высота: в $\mathrm{g}_{2} \mathrm{~V}$ состоянии меньшие значения отмечены на высоте 5-6 м, особи $\mathrm{g}_{3} \mathrm{~V}$ и ss состояния на высоте 3-4 м имеют максимальные значения, минимальные - на высоте 7-8 м. Можно отметить следующую тенденцию: слоевища на высотах 3-4 м и 5-6 м характеризуются минимальными значениями длины почернения корового слоя, максимальными - на высоте 7-8 м.

Число соралей не различается на разных высотах. Взаимодействие факторов: в $\mathrm{g}_{2} \mathrm{~V}$ онтогенетическом состоянии бо́льшее число соралей образуется на высотах 5-6 м и 7-8 м, в $\mathrm{g}_{3} \mathrm{~V}$ состоянии число соралей не различается на разных высотах, y ss особей большее число соралей отмечено на высоте 7-8 м. Длина соралей резко увеличивается с увеличением высоты, в последовательности 3-4 м - 5-6 м - 7-8 м, различия по высотам проявляются в $\mathrm{g}_{2} \mathrm{~V}, \mathrm{~g}_{3} \mathrm{~V}$ и ss состояниях. 


\section{Выводы}

В ходе онтогенеза эвернии сливовой выявлено 4 типа изменения морфометрических признаков: с максимумом на $\mathrm{g}_{3} \mathrm{~V}$ состоянии (длина слоевища, число соралей на одной веточке), с максимумом на генеративных состояниях (число дихотомических ветвлений), с максимумом на $\mathrm{g}_{3} \mathrm{~V}$ и ss состояниях (число отмерших веточек, длина почернения корового слоя, длина соралей). Изменчивость морфологических признаков E. prunastri зависит от стадий развития слоевища и от условий их произрастания. Длина слоевища имеет минимальные размеры на черемухе обыкновенной. Признаки отмирания (число отмерших веточек, длина почернения корового слоя) максимальны на черемухе, что свидетельствует о более ускоренных процессах старения слоевища на данном форофите. Липа сердцелистная является наиболее благоприятным субстратом для развития слоевищ эвернии сливовой. Слоевища E. prunastri, произрастающей на ветвях пихты сибирской, имеют наибольшую длину на высотах 3-4 и 5-6 м, уменьшение размеров слоевища происходит на высоте 7-8 м. С увеличением высоты происходит уменьшение числа отмерших веточек, выявленное в $\mathrm{g}_{3} \mathrm{~V}$ и ss состояниях. Длина соралей у слоевищ, произрастающих на ветвях пихты, увеличивается в последовательности 3 4 м - 5-6 м - 7-8 м, следовательно, на больших высотах образуется большее количество соредий; различия по высотам проявляются в $\mathrm{g}_{2} \mathrm{~V}, \mathrm{~g}_{3} \mathrm{~V}$ и ss состояниях. Значения большинства признаков E. prunastri, произрастающей на правом берегу реки Большая Кокшага, больше, чем на левом берегу, что связано с лучшей освещённостью правобережья. Длина соралей в правобережье больше на дубе черешчатом по сравнению с липой сердцелистной в $\mathrm{g}_{2} \mathrm{~V}$ и $\mathrm{g}_{3} \mathrm{~V}$ онтогенетических состояниях.

\section{СПИСОК ЛИТЕРАТУРЫ:}

1. Fernández-Mendoza F., Domaschke S., García M.A., Jordan P., Martín M.P., Printzen C. Population structure of mycobionts and photobionts of the widespread lichen Cetraria aculeate // Mol. Ecol. 2011. Vol. 20, № 6. P. 1208-1232.

2. Rundel P.W. The role of morphology in the water relations of desert lichens // J. of the Hattori Bot. Lab. 1982. Vol. 53. P. 315-320.

3. Larson D.W. Differential heat sensitivity amongst four populations of the lichen Ramalina menziesii Tayl. // New Phytologist. 1989. Vol. 111, № 1. P. 73-79.

4. Nash T.H, Boucher V.L., Gebauer R., Larson D.W. Morphological and physiological plasticity in Ramalina menziesii: studies with reciprocal transplants between a coastal and inland site // Bibliotheca Lichenologica. 1990. Vol. 38. P. 357-365.

5. Pintado A., Valladares F., Sancho L.G. Exploring phenotypic plasticity in the lichen Ramalina capitata: morphology, water relations and chlorophyll content in north- and south-facing populations // Annals of Botany. 1997. Vol. 80, № 3. P. 345-353.

6. Rikkinen J. Habitat shifts and morphological variation of Pseudevernia furfuracea along a topographical gradient // Symb. Bot. Ups. 1997. Vol. 32, № 1. P. 223 245.

7. Sojo F., Valladares F., Sancho L.G. Structural and physiological plasticity of the lichen Catillaria corym- bose in different microhabitats of the maritime Antarctica // Bryologist. 1997. Vol. 100, № 2. P. 171-179.

8. Jackson H.B., St. Clair L.L., Eggett D.L. Size is not a reliable measure of sexual fecundity in two species of lichenized fungi // Bryologist. 2006. Vol. 109, № 2. P. 157-165.

9. Perez-Ortega S., Fernandez-Mendoza F., Raggio J., Vivas M., Ascaso C., Sancho L.G., Printzen C., Rios A. Extreme phenotypic variation in Cetraria aculeata (lichenized Ascomycota): Adaptation or incidental modification? // Ann. Bot. 2012. Vol. 109, № 6. P. 1133-1148.

10. Rundel P.W. Water relations and morphological variation in Ramalina menziesii Tayl. // Bryologist. 1974. Vol. 77, № 1. P. 23-32.

11. Larson D.W. Morphological variation and development in Ramalina menziesii Tayl. // American Journal of Botany. 1983. Vol. 70, № 5. P. 668-681.

12. Плюснин С.Н. Морфологическая изменчивость лишайника Stereocaulon alpinum (Stereocaulaceae) в тундровых экосистемах // Бот. журн. 2004. Т. 89, № 9. C. 1437-1452.

13. Osyczka P., Rola K., Lenart-Boroń A., Boroń P. High intraspecific genetic and morphological variation in the pioneer lichen Cladonia rei colonising slag dumps // Central European Journal of Biology. 2014. Vol. 9, № 5. P. 579-591.

14. Пауков А.Г., Гулика И.С. Анатомические и морфологические изменения лишайников в антропогенно нарушенных местообитаниях // Развитие идей академика С.С. Шварца в современной экологии. Екатеринбург, 1999. С. 134-140.

15. Osyczka P., Rola K. Phenotypic plasticity of primary thallus in selected Cladonia species (lichenized Ascomycota: Cladoniaceae) // Biologia. 2013. Vol. 68, № 3. P. 365-372.

16. Суетина Ю.Г. Онтогенез и структура популяции Xanthoria parietina (L.) Th. Fr. в различных экологических условиях // Экология. 2001. № 3. С. 203 208.

17. Суетина Ю.Г. Онтогенез и изменчивость морфометрических признаков лишайника Physcia stellaris (L.) Nyl. в городской среде // Экологическая ботаника: наука, образование, прикладные аспекты: междунар. научная конф.: программа и тез. докл. Сыктывкар: Изд-во Сыкт. ун-та, 2002. С. 223-224.

18. Суетина Ю.Г., Глотов Н.В. Онтогенез и морфогенез кустистого лишайника Usnea florida (L.) Weber ex F.H. Wigg. // Онтогенез. 2010. T. 41, № 1. C. $32-40$.

19. Суетина Ю.Г., Глотов Н.В. Изменчивость признаков в онтогенезе эпифитного лишайника $H y$ pogymnia physodes (L.) Nyl. // Онтогенез. 2014. T. 45, № 3. C. 201-206.

20. Суетина Ю.Г., Ямбердова Е.И. Онтогенез и возрастно-виталитетная структура популяции лишайника Evernia prunastri (L.) Ach. // Вестн. Удм. унта. Сер. Биология. Науки о Земле. 2010. Вып. 3. C. 44-52.

21. Глотов Н.В., Суетина Ю.Г., Трубянов А.Б., Ямбердова Е.И., Иванов С.М. Демографическая структура популяции эпифитного лишайника Evernia prunastri (L.) Ach. в липняках Республики Марий Эл // Вестн. Удм. ун-та. Сер. Биология. Науки о Земле. 2012. Вып. 3. С. 41-49.

22. Работнов Т.А. Жизненный цикл многолетних травянистых растений в луговых ценозах // Тр. БИН 
АН СССР. Сер. 3. Геоботаника. М., 1950. Вып. 6. гии и химии: мат-лы всерос. конф. Йошкар-Ола:

C. 7-204.

23. Уранов А.А. Возрастной спектр фитоценопопуляций как функция времени и энергетических волновых процессов // Биологические науки. 1975. № 2. С. 7-34.

24. Гаранина Е.В., Рябинина С.А., Суетина Ю.Г. Оценка микроклиматических условий в разных местообитаниях эвернии сливовой (Evernia prunastri (L.) Ach.) //Актуальные проблемы экологии, биоло-
Мар. гос. ун-т, 2010. С. 163-165.

25. Johansson V., Bergman K.-O., Lättman H., Milberg $\mathrm{P}$. Tree and site quality preferences of six epiphytic lichens growing on oaks in southeastern Sweden // Ann. Bot. Fenn. 2009. Vol. 46, № 6. P. 496-506.

Статья публикуется при поддержке гранта РФФИ (№ 16-04-0119 a).

\title{
ONTOGENETIC VARIABILITY OF MORPHOLOGICAL CHARACTERS OF EVERNIA PRUNASTRI (L.) ACH. ON DIFFERENT SPECIES OF TREES IN DIFFERENT ECOLOGICAL CONDITIONS
} (C) 2017

\author{
Suetina Yulia Gennadjevna, candidate of biological sciences, associate professor of Biology Department \\ Mari State University (Yoshkar-Ola, Russian Federation)
}

\begin{abstract}
The current paper is about the morphological characters variability of the epiphytic lichen Evernia prunastri. The studies were conducted on the territory of the Mari El Republic in the flooded lime-tree forest of the Bolshaya Kokshaga river. The thalli of $E$. prunastri of different ontogenetic states $\left(\mathrm{v}_{1}, \mathrm{v}_{2}, \mathrm{~g}_{1} \mathrm{v}, \mathrm{g}_{2} \mathrm{v}, \mathrm{g}_{3} \mathrm{v}\right.$, ss) were collected on Tilia cordata, Padus avium, Quercus robur at a stem height of 0,5 to $2 \mathrm{~m}$ and on Abies sibirica branches at heights of 3-4 m, 5-6 m, 7-8 m. Tilia cordata is the most favorable substrate for the development of E. prunastri thalli for most of its characters. The character of the thallus development (the length of the thallus) is minimal in Padus avium. The characters of death (the number of dead branches, the length of the cortex blackening area) are maximal on Padus avium, which indicates more accelerated aging processes of the thallus in this phorophyte. The thallus of E. prunastri, which grows on the branches of Abies sibirica, has the largest lengths at heights of 3-4 and 5-6 $\mathrm{m}$ in comparison with the height of 7-8 $\mathrm{m}$. At higher altitudes, longer soralia are formed, hence, more soredia are formed. The values of most characters of E. prunastri, which grows on the right bank of the Bolshaya Kokshaga river are bigger than on the left bank, which is due to differences in the lighting of habitats. The length of the soralia on the right bank (the best lighting) is more in Quercus robur than in Tilia cordata. The variability of morphological characters is manifested in different ways in different ontogenetic states.

Keywords: epiphytic lichen; fruticose lichen; Evernia prunastri; substrate; phorophyte; tree trunk; tree branches; Abies sibirica; Quercus robur; Tilia cordata; Padus avium; ontogeny; ontogenetic states; morphological characters; variability; fitness; ecological conditions; flooded lime-tree forest; Bolshaya Kokshaga river; Mari El Republic.
\end{abstract}

УДК 502.504

Статья поступила в редакцию 04.10.2017

\section{ОЦЕНКА ВОЗДЕЙСТВИЯ НЕФТЕГАЗОДОБЫВАЮЩЕГО ПРЕДПРИЯТИЯ НА ЭКОЛОГИЧЕСКОЕ СОСТОЯНИЕ ПОЧВ БЛИЗЛЕЖАЩЕЙ ТЕРРИТОРИИ}

(C) 2017

Султанова Миляуша Ильнуровна, студент факультета биологии и химии

Шмелёв Николай Александрович, кандидат биологических наук, доцент кафедры биологии и экологии

Исламова Айсылу Айратовна, кандидат биологических наук, доцент кафедры биологии и экологии Бирский филиал Башкирского государственного университета (2. Бирск, Республика Башкортостан, Российская Федераџия)

Аннотация. В статье анализируются результаты исследования почвенного слоя на территории нефтегазодобывающего предприятия. Оценка техногенного воздействия нефти на основные химические и биологические показатели почв дана на основании экспериментальных исследований на территории предприятия. Объектами изучения послужили фоновые (незагрязненные) и загрязненные нефтью почвы. Влияние загрязнения нефтью в природных условиях изучали с помощью сопоставления свойств загрязненных почв с их фоновыми аналогами. Почвенный покров - основной элемент ландшафта - первым принимает на себя «экологический удар». В связи с механическим нарушением и нередко химическим загрязнением происходит постепенная деградация почв, которая стала одной из основных экологических проблем нефтегазодобывающего комплекса. Исследования проводились в апреле - мае 2017 года. В ходе анализа видно, что значительно изменились морфологические признаки почвы. Анализ фитотоксичности почвы с помощью метода биотестирования с применением семян кресс-салата показал высокую степень фитотоксичности почв. Процент гумуса оказался значительно ниже среднего содержания в верхнем горизонте почв. Анализ результатов химического состава показал, что уровень загрязнения почвы тяжелыми металлами низкий, за исключением концентраций кадмия и кобальта. Содержание нефтепродуктов также не превышает ПДК.

Ключевые слова: почвенный слой; нефтегазодобывающее предприятие; структура почвы; лабораторные исследования; сравнительный анализ; тяжелые металлы; морфологические признаки почвы; нефтепродукты; фитотоксичность; кресс-салат; метод биоиндикации; физико-химические методы анализа; предельно допустимая концентрация. 